Report No. BMI-1376

UC-25 Metallurgy and Ceramics (TID 4500 , 15th Ed.)

Contract No. $W-7405 m$ eng -92

SOLUBILITY LIMITS OF YTTRIUM AND THE LANTHANIDE RARE-EARTH ELEMENTS IN CHROMIUM AND CHROMIUM-IRON ALLOYS

by

Seymour G. Epstein

Arthur A. Baver

Ronald F. Dickerson

September 1, 1959

Columbus 1, Ohio 


\section{DISCLAIMER}

This report was prepared as an account of work sponsored by an agency of the United States Government. Neither the United States Government nor any agency Thereof, nor any of their employees, makes any warranty, express or implied, or assumes any legal liability or responsibility for the accuracy, completeness, or usefulness of any information, apparatus, product, or process disclosed, or represents that its use would not infringe privately owned rights. Reference herein to any specific commercial product, process, or service by trade name, trademark, manufacturer, or otherwise does not necessarily constitute or imply its endorsement, recommendation, or favoring by the United States Government or any agency thereof. The views and opinions of authors expressed herein do not necessarily state or reflect those of the United States Government or any agency thereof. 


\section{DISCLAIMER}

Portions of this document may be illegible in electronic image products. Images are produced from the best available original document. 


\section{TABLE OF CONTENTS}

$\underline{\text { Page }}$

ABSTRACT . . . . . . . . . . . . . . . . . . . . . 1

INTRODUCTION . . . . . . . . . . . . . . . . . . . . . 1

EXPERIMENTAL TECHNIQUE . . . . . . . . . . . . . . . . 2

EXPERIMENTAL RESULTS . . . . . . . . . . . . . . . . . . 3

Recoveries .. . . . . . . . . . . . . . . . . 3

Solubility Limits . . . . . . . . . . . . . . . . . . . 6

Metallography ....................... . . . . . 6

DISCUSSION . . . . . . . . . . . . . . . . . . . . . . . 14

REFERENCES . . . . . . . . . . . . . . . . . . . . . 14 


\title{
SOLUBILITY LIMITS OF YTTRIUM AND THE LANTHANIDE RARE-EARTH ELEMENTS IN CHROMIUM AND CHROMIUM-IRON ALLOYS
}

\author{
by
}

S. G. Epstein, A. A. Bauer, and R. F. Dickerson

\begin{abstract}
The solubility limits of yttrium and the lanthanide rare-earth elements in chromium and chronium-iron alloys were investigated at $2300 \mathrm{~F}$ and at room temperaure. Bases of pure chromium and chromium alloyed with 10,25, 50, and $75 w / o$ iron were prepared with additions of cerium, dysprosium, erbium, gadolinium, holmium, lanthanum, lutetium, neodymìm, proseodymium, samarium, terbium, thulium, yiterbium, and yttrium.

Most of the elements investigated are estimated to be soluble to the extent of $0.1 \mathrm{w} / \mathrm{o}$ or less in the base alloys. Dysprosium, erbium, and holmiun exhibit solubilicy limits estimated to be between 0.1 and $0.3 w / 0$. In general, the solubilities of these elements decreased slightly from $2300 \mathrm{~F}$ to room temperature.
\end{abstract}

\section{INTRODUCTION}

Interest in the effects of additions of rare-earth elements on the properties of chromium and chromium-iron alloys has been stimulated by the discovery that small additions of yttrium to chromium greatly improve its high-temperature oxidation resistance. This discovery suggested that the rare earths also might be effective oxidation inhibitors in chromium and chromium-iron alloys. A logical step in a program of study of such effects is the determination of the solubility limits of yttrium and of the rare-earth elements in these base materials. Solubility data are important from the point of view that fabricability of chromium alloys is usually adversely affected if the solubility limit is greatly exceeded, as might occur at the composition required for maximum oxidation resistance. Furthermore, as some of the rare earths considered have relatively low melting and boiling temperatures, it is of importance to know the recovery of these elements that can be expected when they are alloyed with the base materials. In order to provide this information, a research program designed to determine the solubility of cerium, dysprosium, erbium, gadolinium, holmium, lanthanum, lutetium, neodymium, praseodymium, samarium, terbium, thulium, ytterbium, and yttrium in unalloyed chromium and chromium alloyed with 10, 25, 50, and $75 \mathrm{w} / \mathrm{o}$ iron was initiated. 


\section{EXPERIMENTAL TECHNIQUE}

The materials used in this experiment were electrolytic iron, iodide chromium, and commercial high-purity yttrium and rare earths. In preparing the samples, master alloys of chromium and chromium-iron of the desired composition were first arc melted in helium and cast into $100-\mathrm{g}$ buttons. The buttons containing 50 and $75 \mathrm{w} / 0$ iron in chromium were cold rolled to sheet and sheared into small strips for weighing. Buttons containing 10 and 25 w/o iron in chromium would not cold roll, but broke up after one or two passes through the rolls; these were further broken into pieces small enough for sample preparation. Calculated amounts of yttrium and each rare earth were weighed analytically and, with the required amount of the individual master alloys, prepared in 10-g charges. These were arc melted under an atmosphere of helium into buttons, which were flipped and melted six times to insure homogeneity.

The alloys prepared contained charged concentrations of $0.1,0.25$, and $0.5 \mathrm{w} / 0$ yttrium, $0.25,0.5$, and $1.0 \mathrm{w} / 0$ lanthanum, and 0.5 and $1.0 \mathrm{w} / 0$ cerium, erbium, gadolinium, holmium, lutetium, neodymium, praseodymium, terbium, and thulium in the base alloys. It was believed that dysprosium, samarium, and ytterbium would experience poor recoveries, so only $1.0 \mathrm{w} / 0$ additions of these elements were made to chromium and chromium-50 w/o iron-base alloys. Europium was not investigated because of its relatively low boiling point and reported poor recovery. Promethium is produced only as a fission product in nuclear fuels and was not available.

Two pieces were cut from the center of each alloy button to yield two sets of specimens having one specimen of each alloy composition. The sets of alloys were placed in two separate quartz tubes and sealed under an argon atmosphere. These were heated in a resistance furnace to $2300 \mathrm{~F}$ and held at this temperature for $4 \mathrm{hr}$. One tube was then removed, and the specimens were water quenched by breaking the tube directly over a water bath. The tube containing the other set of specimens was furnace cooled to $1100 \mathrm{~F}$, and held at this temperature for 1 week to facilitate precipitation of the equilibrium phases in the specimens. Then this tube was furnace cooled to room temperature.

The specimens were mounted in Bakelite and were ground on 120-, 240-, 400-, and 600-grit silicon carbide grinding papers. Rough polishing was performed on Forstmann's cloth, using first Linde B and then Blue Diamond abrasives. Final polishing was accomplished on microcloth with Linde $B$ abrasive, except for specimens containing yttrium, which were polished with magnesium oxide abrasive. The specimens were examined microscopically after polishing and then were electrolytically etched for 5 sec in a 10 volume per cent oxalic acid solution at $6 \mathrm{v}$, and re-examined. It was observed that most of the specimens contained a bluish gray precipitate of particles which were usually spherical, and which were more or less uniformly distributed throughout the specimen. This precipitate increased in size and amount as the concentration of each rare earth increased in the alloy. Since control specimens of chromium and chromium-iron alloys did not display this precipitate, this second phase was assumed to be yttrium or rare earth either in elemental or combined form. The presence of this second phase, therefore, was taken to indicate that the solubility limit of yttrium or the rare earth in that alloy had been exceeded. 
One sample of chromium and chromium-50 w/o iron alloy containing each of the rare earths was spectrographically analyzed for rare-earth content. The alloy containing the lowest nominal concentration of each rare earth in those cases where the second phase was found, or the highest concentration of rare earth in those cases where no second phase was found, was chosen for analysis. Since all alloys containing thulium appeared to have thulium concentrations only slightly above the solubility limit, all of these alloys were analyzed. All alloys containing yttrium also were analyzed. The analyses are estimated to be accurate to approximately 5 per cent of the reported concentration, with a lower detection limit varying for each rare earth to a minimum of about $0.01 \mathrm{w} / 0$ of the rare earth.

\section{EXPERIMENTAL RESULTS}

The results of this investigation, based upon metallographic examination of specimens, are presented in Table 1. Except for the yttrium-and thulium-containing alloys, which were analyzed at each base-alloy composition, analyses were obtained only for the chromium and chromium-50 w/o iron bases. Solubility limits for these alloys are presented in terms of analyzed concentrations of the yttrium or rare-earth additions. Solubility limits in the remaining 10,25 , and $75 \mathrm{w} / 0$ iron-chromium-base alloys are presented in terms of charged concentrations. An estimate of the actual solubility limit in the alloys which were not analyzed can be made by estimating the recovery from consideration of the recovery in analyzed alloys containing the same addition; similar recoveries can be expected.

\section{$\underline{\text { Recoveries }}$}

As can be seen from Table 1 , the recoveries of the various additions after melting were fairly high, with more than half of the charged addition being recovered in most

cases. However, a few elements experienced very poor recoveries; $0.1 \mathrm{w} / 0$ or les of samarium, thulium, and ytterbium were retained in the alloys. This was expected for samarium and ytterbium because of their relatively low melting and boiling points. Since vapor-pressure data for the rare earths are scarce, the expected recoveries were based on the variations in melting and boiling temperatures of the rare earths compiled from the best information available at the initiation of this study. This information suggested that, in addition to samarium and yttexbium, dysprosium would also experience poor recovery. It was found that $0.2 \mathrm{w} / 0$ dysprosium was retained from $1.0 \mathrm{w} / 0$ charges, which is considerably poorer retention than that of neighboring rare-earth elements in the periodic table, but it is a better recovery than was expected. On the other hand, normal recovery was expected for thulium on the basis of existing data.

More recent data(1) on melting and boiling temperatures of yttrium and the rare earths are presented in Table 2. The boiling temperatures given, although estimated values, are satisfactory for purposes of comparison. It is evident from this table that poorer recoveries of thulium than of dysprosium should have been expected. However,

(1) References are listed on page 14. 
TABLE 1. SOLUBILITY LIMITS OF YTTRIUM AND LANTHANIDE RARE-EARTH ELEMENTS IN CHROMIUM AND CIROMIUM-IRON ALLOYS (a)

\begin{tabular}{|c|c|c|c|c|c|c|c|c|c|c|}
\hline \multirow{3}{*}{$\begin{array}{c}\text { Addition } \\
\text { Element } \\
\end{array}$} & \multicolumn{10}{|c|}{ Solubility Limits in Indicated Chromium Alloy Composition, $w / 0$} \\
\hline & \multicolumn{2}{|c|}{ Unalloyed Chromium } & \multicolumn{2}{|c|}{10 w/o Iron } & \multicolumn{2}{|c|}{$25 \mathrm{w} / \mathrm{O}$ Iron } & \multicolumn{2}{|c|}{$50 \mathrm{w} / \mathrm{O}$ Iron } & \multicolumn{2}{|c|}{75 w/o Iron } \\
\hline & Nominal & Analyzed & Nominal & $\overline{\text { Analyzed }}$ & Nominal & Analyzed & Nominal & Analyzed & Nominal & Analyzed \\
\hline Yterium & $<0.10$ & $<0.10$ & $<0.10$ & $<0.12$ & $<0.10$ & $<0.08$ & $\approx 0.10$ & $\approx 0.09$ & $<0.10$ & $<0.07$ \\
\hline Lanthanum & $<0.25$ & $<0.12$ & $<<0.25$ & $\infty$ & $<<0.25$ & $-\infty$ & $<0.25$ & $<0.11$ & $<0.25$ & $\infty \rightarrow \infty$ \\
\hline Cerium & $<0.5$ & $<0.34$ & $<0.5$ & $\rightarrow$ & $<<0.5$ & $-m$ & $<<0.5$ & $<<0.26$ & $<0.5$ & $\infty$ \\
\hline Praseodymium & $<<0.5$ & $<<0.37$ & $<<0.5$ & $-\infty$ & $<<0.5$ & $\infty$ & $<<0.5$ & $<<0.25$ & $<<0.5$ & isem \\
\hline Neodymium & $<<0.5$ & $<<0.30$ & $<<0.5$ & $\infty$ & $<<0.5$ & $\infty$ & $<<0.5$ & $<<0.48$ & $<<0.5$ & $\infty$ \\
\hline Samarium & $>1.0$ & (b) & $\infty$ & $\infty$ & $\infty$ & $\infty$ & $\sim 1.0$ & -0.07 & $-\infty$ & $\infty$ \\
\hline Gadolinium & $<<0.5$ & $<<0.25$ & $<<0.5$ & $\infty$ & $<<0.5$ & $\infty$ & $<<0.5$ & $<0.28$ & $<0.5$ & $\infty$ \\
\hline Terbiurn & $<0.5$ & $<<0.39$ & $\ll<0.5$ & $\infty$ & $<<0.5$ & $-\infty$ & $<<0.5$ & $<0.33$ & $<<0.5$ & $-\infty$ \\
\hline Dysprosium & $\sim 1.0$ & $\sim 0.20$ & $\infty$ & $\infty$ & $\infty$ & $\infty$ & $\sim 1.0$ & -0.20 & $\infty$ & $-\infty$ \\
\hline Holmium & $<0.5$ & $<0.22$ & $<0.5$ & $\infty$ & $<0.5$ & - & $<0.5$ & $<0.31$ & $<0.5$ & $\infty$ \\
\hline Erbium & $<0.5$ & $<0.33$ & $<0.5$ & $\infty$ & $<0.5$ & $\infty$ & $<0.5$ & $<0.43$ & $<0.5$ & $-\infty$ \\
\hline Thulium & $>1.0$ & $>0.03$ & $\sim 1.0$ & $\sim 0.06$ & $\approx 0.5$ & $\sim 0.085$ & $\sim 0.5$ & $\sim 0.10$ & $\sim 0.5$ & $\sim 0.09$ \\
\hline Ytterbium & $>1.0$ & (b) & $\infty$ & - & $-\infty$ & $-\infty$ & $>1.0$ & $>0.01$ & $\infty$ & meses \\
\hline Lutetium & $\ll 0.5$ & $<<0.37$ & $<<0.5$ & $m \infty$ & $<0.5$ & $-\infty$ & $<<0.5$ & $<<0.48$ & $\ll 0.5$ & $\infty$ \\
\hline
\end{tabular}

(a) Solubility limits at $2300 \mathrm{~F}$ and room temperature. Alloys at room temperature contained the same phases as at $2300 \mathrm{~F}$, but generally contained slightly more second phase.

(b) No rare earth found in this alloy. 
TABLE 2. SELECTED PHYSICAL PROPERTIES OF YTTRIUM AND THE LANTHANIDE RARE EARTHS(a)

\begin{tabular}{|c|c|c|c|c|c|}
\hline Element & $\begin{array}{l}\text { Atomic } \\
\text { Number }\end{array}$ & $\begin{array}{l}\text { Melting } \\
\text { Point, } C\end{array}$ & $\begin{array}{c}\text { Boiling } \\
\text { Point }(b) \cdot C\end{array}$ & $\begin{array}{c}\text { Room - } \\
\text { Temperature } \\
\text { Structure }\end{array}$ & $\begin{array}{c}\text { Atomic } \\
\text { Diameter. A }\end{array}$ \\
\hline Ytrrum & 39 & 1552 & 3030 & HCP & 3.60 \\
\hline Lanthanum & 57 & $920 \pm 5$ & 4230 & $\mathrm{HCP}$ & 3.74 \\
\hline Cerium & 58 & $804 \pm 5$ & 2930 & FCC & 3.63 \\
\hline Praseodymum & 59 & $935 \pm 5$ & 3020 & $\mathrm{HCP}$ & 3.64 \\
\hline Neodymum & 60 & $1024 \div 5$ & 3180 & $\mathrm{HCP}$ & 3.64 \\
\hline Sanarium & 62 & $1052 \div 5$ & 1630 & Rhom. & 3.61 \\
\hline Europium & 63 & $826 \pm 10$ & 1490 & $\mathrm{BCC}$ & 4.08 \\
\hline Gadolinium & 64 & $1350 \pm 20$ & 2730 & $\mathrm{HCP}$ & 3.59 \\
\hline Terbum & 65 & 1360 & 2530 & $\mathrm{HCP}$ & 3.55 \\
\hline Dysprosium & 66 & $1485 \pm 20$ & 2330 & $\mathrm{HCP}$ & 3.54 \\
\hline Holmium & 67 & 1490 & 2330 & $\mathrm{HCP}$ & 3.52 \\
\hline Erbium & 68 & $1500 \cdot 1550$ & 2630 & $\mathrm{HCP}$ & 3.50 \\
\hline Thulium & 69 & $1550-1600$ & 2130 & $\mathrm{HCP}$ & 3.18 \\
\hline Ytterbium & 70 & $824 \pm 5$ & 1530 & $\mathrm{FCC}$ & 3.87 \\
\hline Lutetium & 71 & $1650-1750$ & 1930 & $\mathrm{HCP}$ & 3.47 \\
\hline
\end{tabular}

(a) From Reference (1).

(b) Estimated values. 
an anomaly is indicated, in that the recent data suggest that lutetium should not exhibit the excellent recoveries that it did.

\section{Solubility Limits}

The solubility limits presented in Table 1 are given in terms of the concentration of a particular addition in an alloy. Since only a small number of alloys were prepared with any particular rare earth at each base-alloy composition, the solubility limits cannot be more closely defined. In most cases, the lowest concentration of rare-earth adition was found to exceed the solubility limit. In these cases, the solubility limit was estimated more closely by observing the amounts of second phase in the alloys. Where a small amount of second phase was observed in a uniform distribution, the limit in that alloy was estimated to be "less than" the reported concentration. A larger amount of coarser particles led to an estimate for the solubility limit of "much less than" the analyzed or nominal concentration of the rare earth in that alloy. The symbols representing "less than" and "much less than" are used in Table 1.

In a few cases, as for dysprosium in chromium, for yttrium, samarium, and dysprosium in chromium-50 w/o iron, and for thulium in all the chromium-iron alloys, the amount of addition retained just slightly exceeded the limit of solubility. This was concluded by the appearance of only a few particles of second phase scattered through the alloy structure. Here, again, the amounts of second phase observed differed slightly, but the precipitate was so sparse that differentiation of the amounts was difficult. These alloys are represented in Table 1 as containing yttrium or rare earth in a concentration "approximately" that of the solubility limit, although the limit has been exceeded. Only a very few alloys contained no second phase; and this is attributed to low retention of the rare earths during melting of these alloys.

The values in Table 1 are equally valid for the solubilities at $2300 \mathrm{~F}$ and at room temperature. The specimens that were furnace cooled showed the same structures as quenched specimens from the same alloy buttons. However, the furnace-cooled specimens in general contained slightly more second phase. This observation indicates a small decrease in solubility from $2300 \mathrm{~F}$ to room temperature.

\section{Metallography}

Photomicrographs illustrating the type of microstructure found in chromium and chromium-iron alloys containing yttrium and lanthanide rare-earth additions are shown in Figures 1 through 6 . The photomicrographs were selected primarily to show the yttrium-and rare-earth-rich precipitate, and are not always representative of the average amount of precipitate appearing over the entire surface of the alloy. While the alloys were usually homogeneous, there was a tendency in some cases for the second phase to appear in clumps rather than as a uniform dispersion.

Figure 1 shows several examples of a relatively fine metallic phase in fairly uniform dispersion. The presence of a second phase, metallic in appearance and believed 
a. Chromium-0.12 w/o Lanthanum Water Quenched From $2300 \mathrm{~F}$

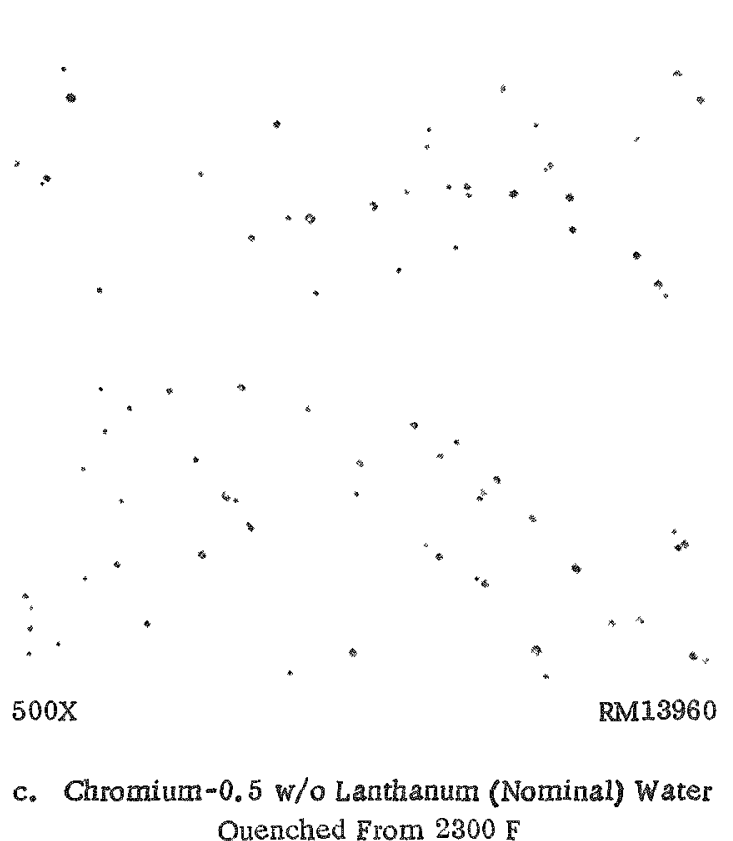
Quenched From $2300 \mathrm{~F}$ b. Chromium -0.12 w/o Lanthanum Furnace Cooled From $2300 \mathrm{~F}$

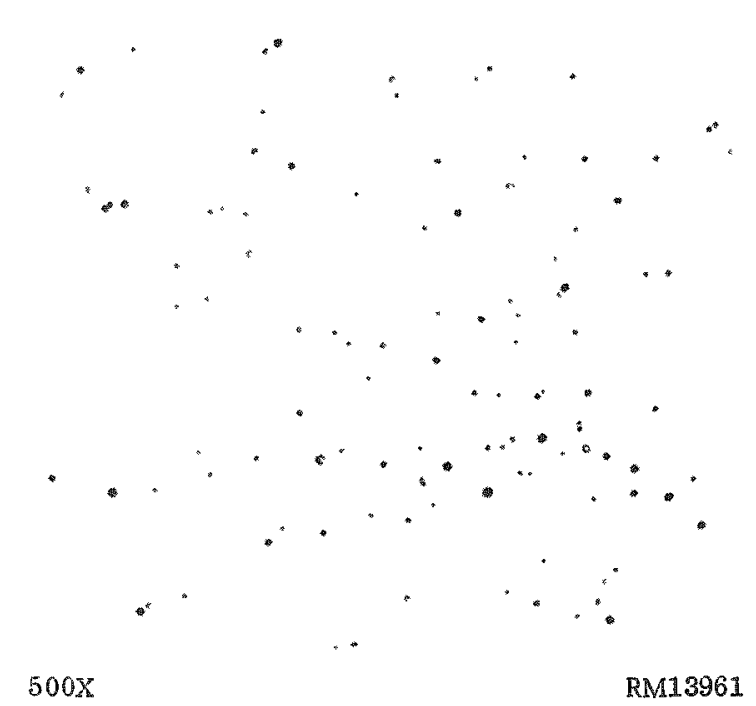

d. Chromium-1.0 W/o Lanthanum (Nominal) Water Quenched From $2300 \mathrm{~F}$

FIGURE 1. MICROSTRUCTURES OF CHROMIUMI-LANTHANUM COMPOSITIONS

Increased lanthanum solubility at $2300 \mathrm{~F}$ is indicated by the greater amount of second phase, probably metallic lanthanum, visible in the furnace-cooled chromium-0.12 w/o lanthanum specimen. The identification of the second phase as metallic lanthanum is supported by the increase in the second phase with higher lanthanum addition visible in the three water-quenched structures. All structures are shown as polished. 


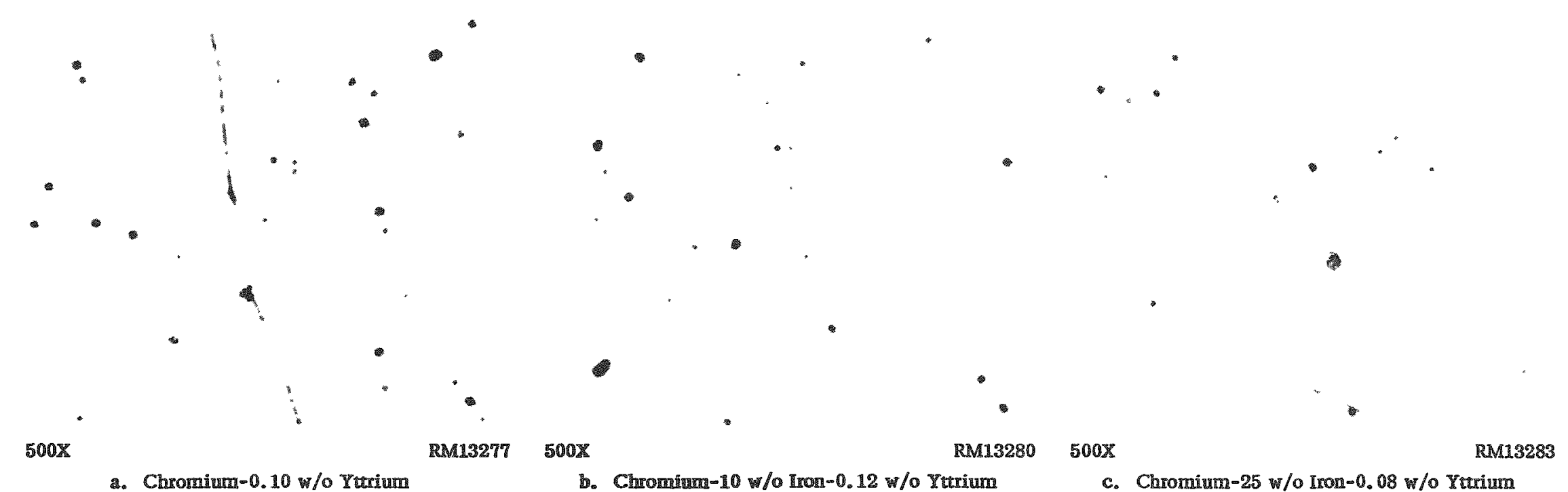

a. Chrornium-0.10 w/0 Yetrium

b. Chroming- $10 \mathrm{w} / 0$ Iron-0.12 $\mathrm{w} / 0$ Trtrium

c. Chromium-25 $\mathrm{w} / \mathrm{o}$ Iron $-0.08 \mathrm{w} / \mathrm{0}$ Yturium

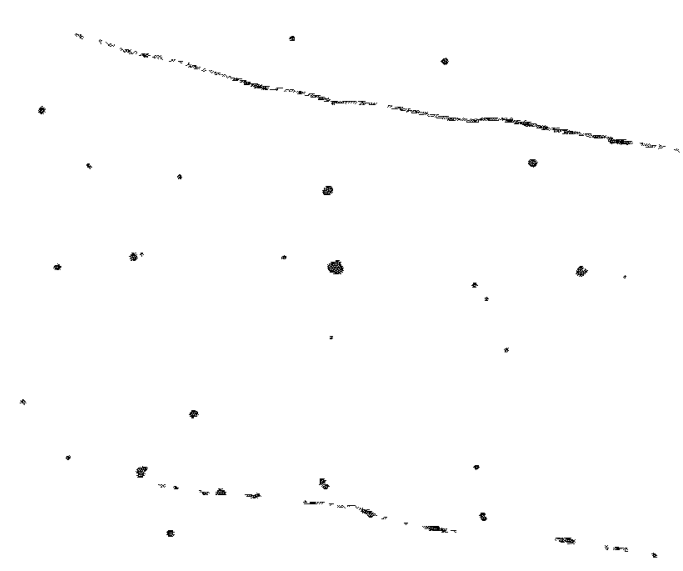

d. Chromium-50 W/0 Iron-0.02 w/0 Ytrizm

FIGURE 2. STRUCTURES OF CFROMHUM AND CHROMUM-IRON ALLOYS CONTAINING APPROXIMATEL 0.1 W/0 YTTRIUM WATER QUENCHED FROM 2300 F

The second phase in the chromium and chromium-iron bases containing up to $50 \mathrm{w} / \mathrm{o}$ iron is believed to be elemental ytarium. In the chromium75 w/o iron-0.07 w/o ytuin composition the second phase a similar yttium addition also displayed an yturium-1ron-conpound second phase. All specimens were etched with a 10 volume per cent oxalic acid solution. 


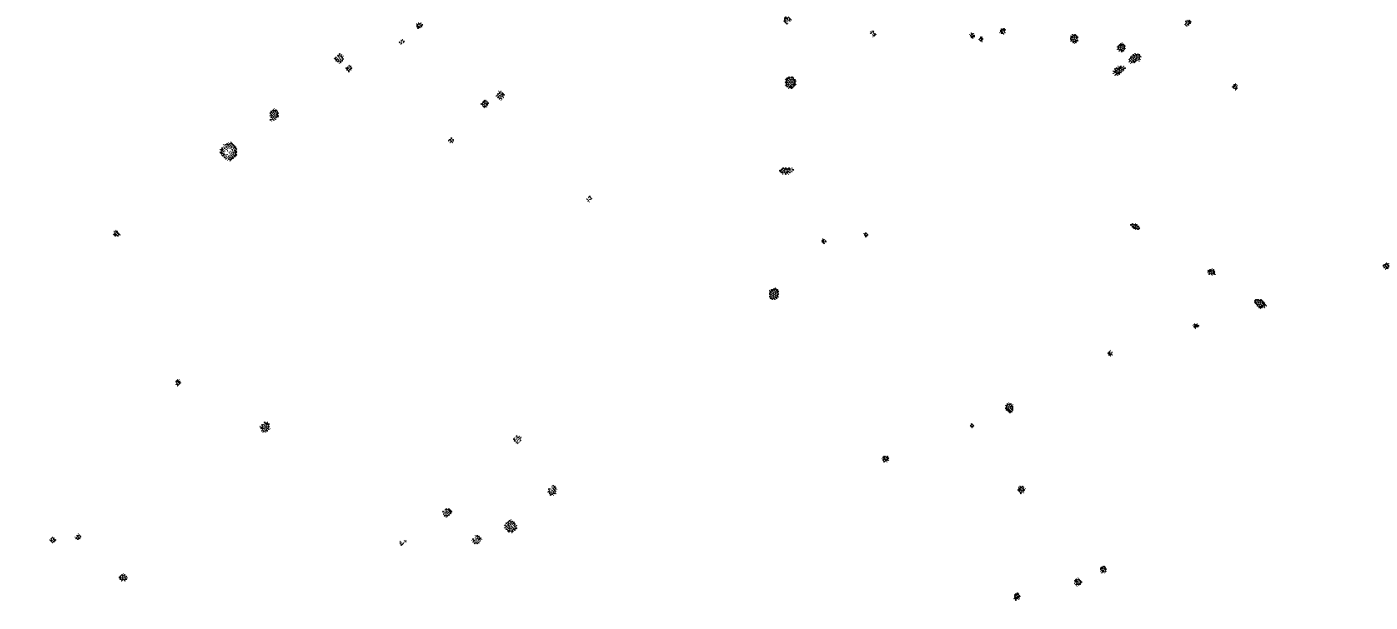

$500 \mathrm{X}$

RM12135

$500 x$

RM12130

a. Chromium Containing 0.34 w/o Cerium

b. Chromium Containing $0.37 \mathrm{~W} / \mathrm{O}$ Praseodymium

$500 \mathrm{x}$

RM12142

$500 \mathrm{x}$

RM12132

c. Chromium Containing $0.30 \mathrm{w} / \mathrm{o}$ Neodymium

d. Chromium Containing 0.37 w/o Lutetium

FIGURE 3. TYPICAL STRUCTURES OF CHROMIUM-CERUM, -PRASEODYMIUM, -NEODYMUM, AND -LUTETIUM COMPOSITIONS W ATER QUENCHED FROM $2300 \mathrm{~F}$

The second-phase structures are relatively coarse precipitates rich in the rare-earth addition. The solubility limits are believed to be much less than the concentrations of rare earths retained in these specimens. All specimens are shown as polished. 
a. Chromium Containing 0.25 w/o Gadolinium

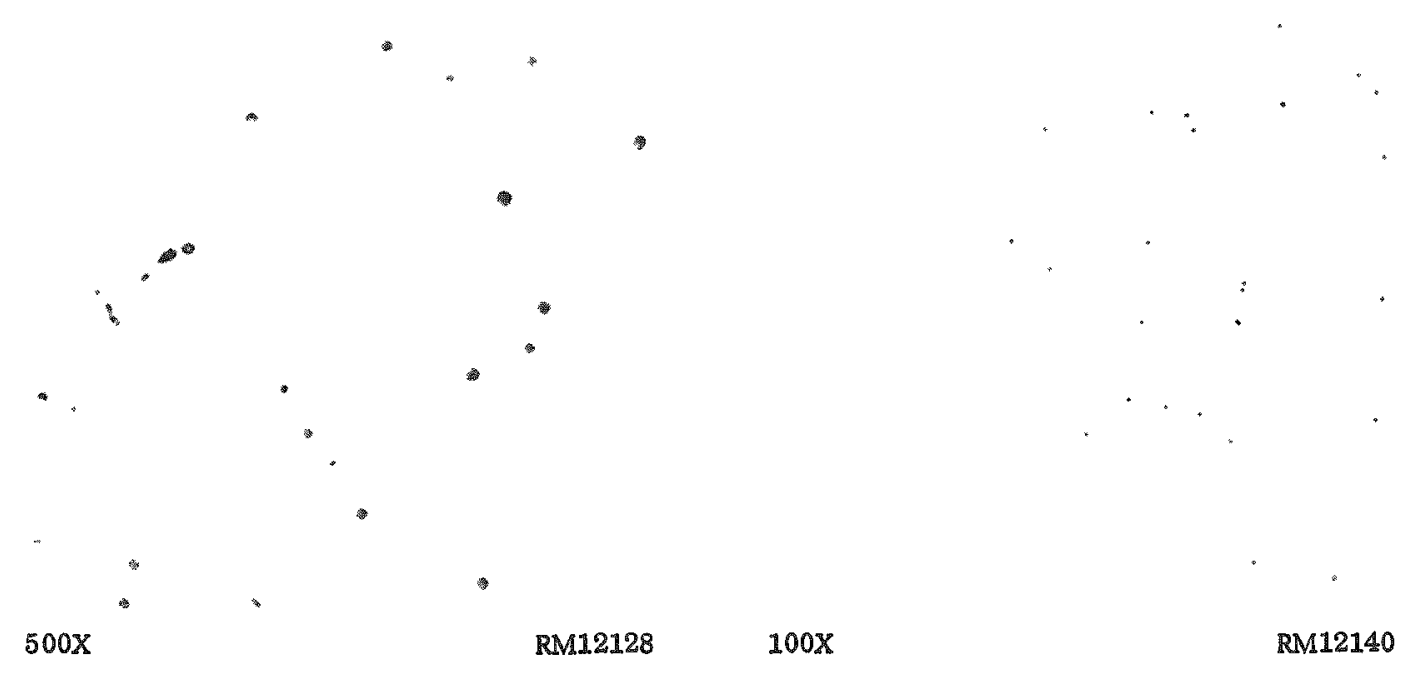

b. Chromium Containing $0.39 \mathrm{w} / \mathrm{O}$ Terbium

\section{FIGURE 4. STRUCTURES OF CHROMIUM-GADOLINIUM AND CHROMIUM-TERBIUM ALLOYS WATER QUENCHED FROM 2300 F}

The concentrations of gadolinium and terbium greatly exceed the solubility of these rare earths in chromium. The $100 \mathrm{X}$ photomicrographs illustrate the uniform distribution of the precipitates. All specimens are shown as polished. 


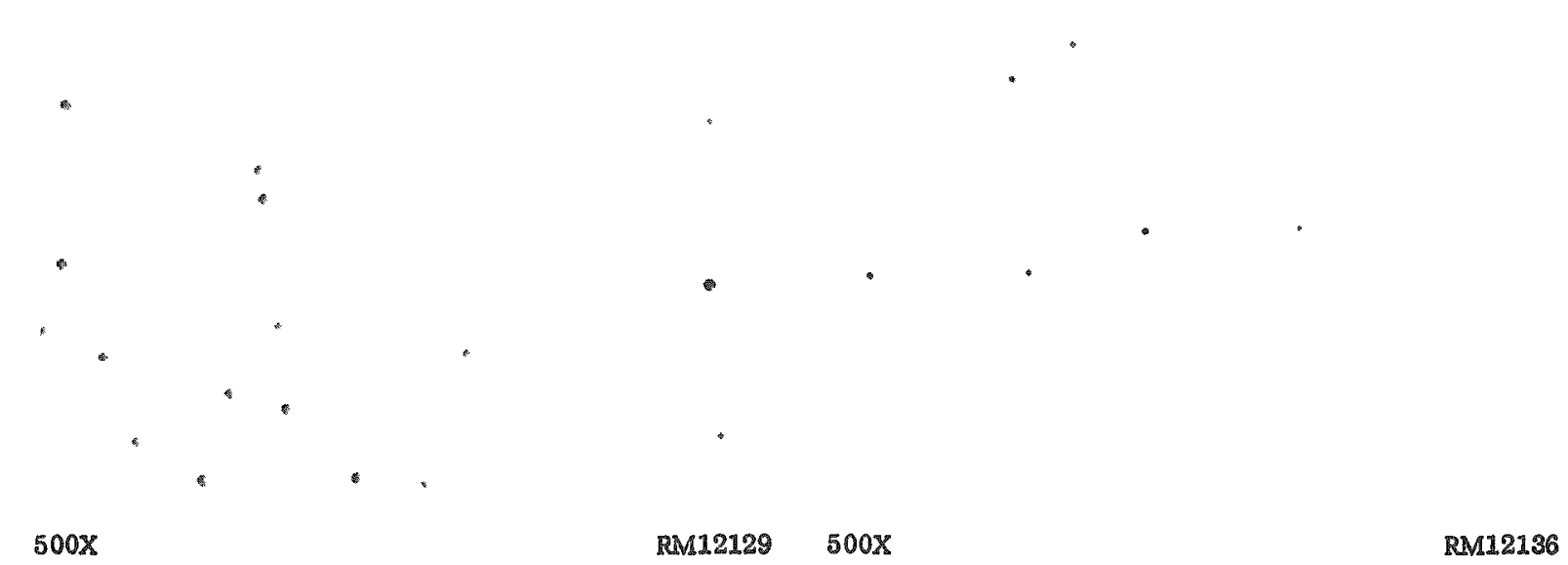

a. Chromium Containing 0.22 w/o Holmium

b. Chromium Containing 0.33 w/o Erbium

M12136

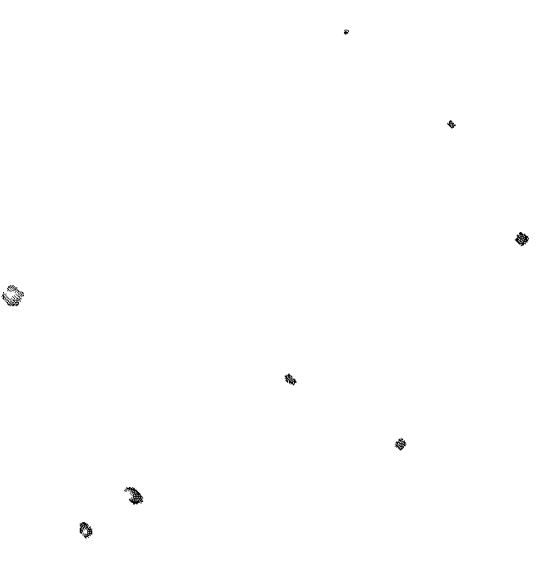

$500 \mathrm{x}$

c. Chromium Containing $0.20 \mathrm{w} / \mathrm{o}$ Dysprosium

d. Chromium $-10 \mathrm{w} / \mathrm{o}$ Iron Containing $0.06 \mathrm{w} / \mathrm{o}$ Thulium

FIGURE 5. STRUCTURES OF CHROMUM-HOLMUM, -FRBIUM, AND -DYSPROSIUM, AND CHROMIUM-IRONTHULIUM COMPOSIIIONS WATER QUENCHED FROM $2300 \mathrm{~F}$

The small amount of second phase in the chromium-holmium and chromium-erbium alloys indicated that the concentrations just exceeded their solubility limits. The holmium-rich precipitate was very inhomogeneously distribured and the photomicrograph shows an area where the phase was especially abundant. The extreme scarcity of a second phase in the chromium-dysprosium and chromium-ironthulium alloys indicated that the recovered concentrations were at the approximate solubility limits. The chromium-iron-thulium specimen was etched with a 10 volume per cent oxalic acid solution; the others are shown as polished. 
$500 x$

RM12141 500X

RM12134

a. Chromium in Which 1.0 w/o Samarium Was Charged

b. Chromium $-50 \mathrm{w} / 0$ Iron Containing $0.07 \mathrm{w} / \mathrm{o}$ Samarium

FIGURE 6. STRUCTURES OF CHROMIUM-SAMARIUM AND CHROMIUMIRON -SAMARIUM ALLOYS WATER QUENCHED FROM 2300 F

The absence of a second phase in the chromium-samarium composition indicated that the solubility limit probably was not exceeded. Very little second phase was observed in the chromium-iron-samarium, indicating that the recovered concentration was near the solubility limit. The chromiumsamarium specimen was etched in 10 volume per cent oxalic acid solution; the other is shown as polished. 
to be metallic lanthanum, indicates that the solubility limit is exceeded. Slightly more second phase can be observed in the specimen which was furnace cooled (Figure 1b) than in the specimen of the same lanthanum content which was water quenched (Figure la) from $2300 \mathrm{~F}$. Figures $1 \mathrm{c}$ and $\mathrm{ld}$ show that the second phase increases in amount as the lanthanum concentration increases in the alloy, supporting the belief that the second phase is lanthanum metal.

Alloys containing yttrium additions are shown in Figure 2; all of these alloys, which contain approximately $0.1 \mathrm{w} / 0$ yttrium, exhibit second-phase particles. The particles in the water-quenched alloys having up to $50 \mathrm{w} / 0$ iron are very similar in appearance to those appearing in alloys containing rare-earth additions, and are believed to be elemental ytrium. In chromium-75 w/o iron alloys and in chromium-50 w/o iron alloys which were furnace cooled, however, a phase of a different nature is evident. This phase is believed to be one of the yttrium-iron compounds which form in high-iron ternary iron-chromium-yttrium alloys.(2)

Figure 3 illustrates structures containing relatively coarse, homogeneous precipitate rich in cerium, praseodymium, neodymium, and lutetium. The solubility limits of the rare earths in these alloys are estimated to be much less than the concentrations of rare earths retained in these specimens. The neodymium-rich precipitate shown in Figure $3 \mathrm{c}$ is somewhat finer than the others, but is more uniformly distributed throughout the structure. The concentrations of gadolinium and terbium in chromium, shown in Figure 4, also greatly exceed the solubility limits of these elements in chromium. Low-magnification photomicrographs are included to illustrate the uniform distribution of the second phase in these alloys.

The small amounts of second phase in the chromium alloys containing holmium and erbium, shown in Figures $5 a$ and $5 b$, indicated that the concentrations of these elements just exceed their solubility limits in the chromium. Although the holmium-rich precipitate is fairly coarse and abundant in the area shown, it was very inhomogeneously distributed. The dysprosium-containing phase depicted in Figure $5 \mathrm{c}$ is extremely fine, and the phase rich in thulium depicted in Figure 5d consists of only a few particles. Therefore, the recovered concentrations of these two elements are believed to be approximately at the solubility limits in chromium.

Figure 6 depicts alloys of chromium and chromium-50 w/o iron in which $1.0 \mathrm{w} / 0$ samarium had been charged. Spectrographic analysis failed to detect any samarium in the chromium alloy within the limit of detection for samarium (0.03 w/o). Figure 6a shows that no precipitate formed and that probably the solubility limit of samarium in chromium was not exceeded. A second phase was not revealed even by etching. In the chromium $-50 \mathrm{w} / 0$ iron alloy, however, $0.07 \mathrm{w} / 0$ samarium was reported to be recovered, and the small amount of precipitate that can be observed in Figure $6 \mathrm{~b}$ indicates that this concentration is approximately that of the solubility limit. 


\section{DISCUSSION}

In general the solubility of yttrium and the rare earths in chromium and chromium-10, $-25,-50$, and $-75 \mathrm{w} / 0$ iron alloys is estimated as being less than $0.1 \mathrm{w} / 0$. This limited solubility might be expected on the basis of the marked difference in atomic diameter between the rare-earth element additions and the base-alloy elements. The atomic diameters of yttrium and the rare earths, as shown in Table 2 , vary between 3.47 and $4.08 \mathrm{~A}$, while the atomic diameters of iron and chromium are 2.48 and $2.50 \mathrm{~A}$, respectively. Thus the difference in atomic diameter between solute and solvent atoms exceeds 35 per cent, a difference which precludes the possibility of extensive solid solution.

Also, since the atomic diameters of the lanthanide rare earths decrease, as the atomic numbers of these elements increase, from $3.74 \mathrm{~A}$ for lanthanum to $3.47 \mathrm{~A}$ for lutetium, the solubilities of the rare earths would be expected to increase with atomic number. This has also been observed to some extent based on the slightly greater solubility of dysprosium, holmium, and erbium (estimated as being in the range of 0.1 to $0.3 \mathrm{w} / 0)$. However, thulium showed a solubility of less than $0.1 \mathrm{w} / 0$, and the solubility of lutetium also appears to be relatively small. It is, however, a fairly good approximation to conclude that the rare-earth elements of lower atomic number are slightly less soluble than those of higher atomic number. Ytterbium, with an atomic diameter of 3.87 A deviates from the general trend and should be quite insoluble. However, ytterbium could not be retained in sufficient concentration to determine the solubility limit.

Ytrium, with an atomic diameter of $3.60 \mathrm{~A}$, was also found to exceed its solubility limit in chromium and chromium-iron alloys at a concentration of less than $0.1 \mathrm{w} / \mathrm{o}$.

\section{REFERENCES}

(1) Howes, R. B., "The Rare Earths", Metal Progress, 75 (6), 108-112B (June, 1959).

(2) Farkas, M. S., BMI, private communication (1959). 